\title{
DIGITALIZAÇÃO E A LUTA PELA LINGUAGEM
}

\section{DIGITALIZATION AND THE FIGHT FOR LANGUAGE}

\section{Amanda Diniz Vallada*}

\section{RESUMO}

O objetivo deste artigo é refletir sobre o cenário atual da comunicação digital a partir de e em direção a visões de linguagem que se mantenham atentas às transformações sociolinguísticas motivadas pela digitalização. Para isso, a partir de autoras/es como Blommaert (2008), boyd e Crawford (2012) e Brooker et al. (2016), conceituo e discuto brevemente sobre dois pontos importantes que influenciam os dados e análise das mais diversas pesquisas em Linguística, mas que são, com frequência, deixados em segundo plano: big data e affordance. Em seguida, argumento em favor de visões de linguagem que não sejam nem antropocêntricas, nem universalistas, e que contemplem o contato entre humano e digital, retomando as contribuições de Irvine $(1996 ;$ 2017), Pratt (2013) e Martins e Viana (2019). Palavras-chave: big data; affordance; visões de linguagem.

\section{ABSTRACT}

The purpose of this article is to reflect on the current scenario of digital communication from and towards views of language that remain attentive to the sociolinguistic transformations motivated by digitalization. In order to that, drawing from authors such as Blommaert (2008), boyd and Crawford (2012) and Brooker et al. (2016), I conceptualize and briefly discuss two important points that influence data and analysis of most diverse linguistic researches, but which are often left in the background: big data and affordance. Then, I argue in favor of views of language that are neither anthropocentric nor universalist, and that contemplate the contact between human and digital, resuming the contributions of Irvine (1996; 2017), Pratt (2013) and Martins and Viana (2019).

Keywords: big data; affordance; views of language.

\section{INTRODUÇÃO}

A publicação de Virtual Etbnograpby por Christine Hine (2000), bióloga e socióloga da ciência, marcou o campo dos trabalhos que analisavam a "comunicação mediada por computador". A proposta de Hine era desenvolver um referencial metodológico para a abordagem etnográfica empregada para lidar com a complexidade das interações mediadas por computador, apontando as vantagens e desvantagens de unir etnografia e virtualidade. Dentre as vantagens, Hine (2000) argumenta que a etnografia é atrativa por conta da densidade da descrição e da

\footnotetext{
* Universidade Federal de Goiás, UFG, Goiânia, GO, Brasil. amandavallada@hotmail.com Orcid: https://orcid.org/0000-0002-5512-6087
} 
falta de sustentação em hipóteses anteriores à pesquisa. Nesse sentido, a etnografia virtual se mostra promissora para ajudar a responder perguntas como: "de que forma a Internet afeta a organização das relações sociais no tempo e no espaço?", "existe uma fronteira entre online e offline?", e ainda "como as identidades são performadas e experienciadas, e como julgar sua autenticidade?" (HINE, 2000, p. 8)1.

Mantendo em vista o seu propósito, Hine não deixa de apontar os problemas que a etnografia fornece às pesquisas sobre o uso da internet. Ela argumenta, contudo, que estes são problemas apenas para visões tradicionalistas de etnografias não-críticas, cuja principal aspiração se tornou alcançar "realismo" e "objetividade" para se posicionar diante das críticas de bases positivistas feitas por pesquisadoras/ es que fazem uso de métodos quantitativos. Para essas, a centralidade da interação face a face e da presença física da/o etnógrafa/o no campo (físico) de pesquisa mantém os dados selecionados offline como mais autênticos e confiáveis do que os dados selecionados online (HINE, 2000): se a performance das/dos participantes de pesquisa nas interações com a/o etnógrafa/o são congruentes com a performance observada pela/o etnógrafa/o em outros momentos, então o dado é autêntico e confiável. Dessa forma, a impossibilidade de estar fisicamente presente no campo de pesquisa online macularia a autoridade etnográfica - ou seja, a autoridade e neutralidade que a/o etnógrafa/o supostamente tem para determinar o que existe e o que não existe em seu campo de pesquisa.

Christine Hine alcançou seu objetivo: seu livro de 2000 continua sendo, até hoje, referência de metodologia para pesquisadoras e pesquisadores que se voltam a analisar dados online e, por vezes, a única referência de metodologia de etnografia virtual ou digital² (BIONDO, 2019; BORGES \& MELO, 2019; SILVA, 2019). No entanto, a comunicação (pós) digital de 2020 em muito se difere da comunicação digital de 2000. Aliás, muitos trabalhos de etnografia digital têm sido feitos no sentido de discutir sobre o cenário atual da internet e das tecnologias digitais, especialmente no que tange a questões de contexto e contextualização, como audiência, colapso de contexto, dinâmica online-offline e big data (MARWICK \& boyd, 2010; RYMES, 2012; VARIS, 2014, HINE, 2015; SZABLA \& BLOMMAERT, 2018; BLOMMAERT, SMITS \& YACOUBI).

1. Todas as citações de originais em língua estrangeira foram traduzidas por mim para fins exclusivos deste artigo.

2. Piia Varis e Mingyi Hou (2020) explicam que o termo etnografia virtual se refere a pesquisas que excluem a dimensão offline e que fazem a distinção entre o online e o offline relevante logo de início. Já o termo etnografia digital comporta tanto os dados online quanto os offline, na medida que se interessa pela "mensagem" online e pelas circunstâncias offline em/por que ela foi emitida, não separando a priori o online do offline. Por esta razão, opto, a partir de agora, por usar neste artigo somente o rótulo etnografia digital. 
Em texto recente, Jan Blommaert (2019, p. 1) chama atenção para as novas práticas de comunicação na era pós-digital:

\begin{abstract}
As infraestruturas digitais se tornaram parte do que convencionalmente se chama de 'estruturas sociais' - os condutores profundos, genéricos e frequentemente invisíveis por trás da conduta social - e tais infraestruturas demandam agora muito mais atenção nas pesquisas sobre mensagens e meios (cf. ARNAUT, KARREBACK \& SPOTTI, 2017). De forma concreta: não apenas o conteúdo deve ser central na pesquisa discurso-analítica, mas os sistemas de comunicação e a maneira com que eles moldam novas condições sociolinguísticas para produção, circulação e uptake de discursos, novos recursos, novos atores e novas relações entre os atores. (MALY, 2018)
\end{abstract}

Na esteira dessa proposta, o objetivo deste artigo é refletir sobre o cenário atual da comunicação digital a partir de e em direção a visões de linguagem que se mantenham atentas às transformações sociolinguísticas motivadas pela digitalização. Isto é o que faço na seção 2. Antes, na seção 1, conceituo e discuto brevemente sobre dois pontos de extrema importância que impactam de maneira considerável os corpora de análise das mais diversas pesquisas em Linguística, mas que são, com frequência, deixados em segundo plano: big data e affordance. Concluo retomando a proposta do artigo, e chamo a outras discussões sobre digitalização e linguagem.

\title{
1. BIG DATA E AFFORDANCE DIGITAL: UM CONTEXTO ESQUECIDO ATUALIZADO COM SUCESSO
}

$\mathrm{O}$ big data, fundamentado em três aspectos, os $3 \mathrm{Vs}$ (volume, velocidade e variedade), consiste em "conteúdos e formatos diversos [...] acumulados em grande quantidade, com rapidez crescente" (SANTOS, 2016, p. 25). Contudo, big data não se refere exclusivamente a uma imensa quantidade de dados. danah boyd e Kate Crawford (2012, p. 663) entendem que "big data é menos sobre dados em grande quantidade do que é sobre uma capacidade de pesquisar, agregar, e fazer referência cruzada de vários conjuntos de dados".

As diversas finalidades de uso do big data têm se expandido ao longo dos últimos anos, configurando o fenômeno social da dadificação - a coleta e manipulação de dados digitais referentes à vida cotidiana de cada pessoa (BUZATO, 2018). Organizações de monitoramento de doenças usam o big data para rastrear a proliferação de epidemias e fornecer estratégias para o controle dessas doenças (BANSAL et al., 2016), e forças policiais em várias partes do mundo têm usado o big data para policiamento preditivo (MUTSAERS, 2017). O big data também tem função importante nas estratégias de campanhas eleitorais: em 2012, estrategistas da campanha de reeleição de Barack Obama usaram dados em massa para conquistar 
votos e apoio financeiro (SANTOS, 2016); em 2016, a empresa de marketing Cambridge Analytica usou o big data para estruturar cerca de sete mil informações sobre cada eleitora/or estadunidense e fornecer propaganda eleitoral sob medida para cada pessoa (micromarketing) na campanha de Donald Trump (FLORES, 2017).

Os efeitos do big data estão também no modo como enxergamos a ciência. Questões chaves sobre conhecimento, pesquisa, informação e realidade, lembram boyd e Crawford (2012), são reenquadradas por conta do big data. De fato, foram feitos certos questionamentos sobre a pertinência das Ciências Sociais e dos modelos de hipótese da Física e da Biologia na era dos dados em larga escala:

De lado com toda teoria do comportamento humano, da linguística à sociologia. Esqueça taxonomia, ontologia, e psicologia. Quem sabe por que as pessoas fazem o que fazem? A questão é que elas fazem, e podemos traçar e mensurar isso com fidelidade sem precedentes. Com dados suficientes, os números falam por si. [...] Nós podemos analisar os dados sem ter hipóteses do que eles podem mostrar. Podemos lançar os números nos maiores clusters que o mundo já viu e deixar que algoritmos estatísticos encontrem padrões onde a ciência não consegue encontrar. (ANDERSON, 2008)

Porém, o big data apresenta suas próprias falhas. Muitas das plataformas usadas para seleção de dados de interação online, como Facebook e Twitter, têm ferramentas de busca e arquivamento pouco avançadas, que dificultam e até mesmo impossibilitam o acesso a dados mais antigos e, portanto, condicionam que pesquisadoras/es foquem em interações mais recentes (boyd \& Crawford, 2012). Se os números falam por si, como saber o que eles falam quando não é possível chegar até eles?

Esse último ponto nos leva à questão do affordance digital. O psicólogo James Gibson usou a palavra do inglês para se referir ao fato de que o design de um meio ou objeto influencia as próprias interações entre sujeito e meio, sujeito e objeto (SANTOS, 2016). A noção de affordance, todavia, não é determinista: "um affordance é apenas uma possibilidade que pode ou não ser aceita" (KEANE \& SILVERSTEIN, 2017, p. 34). O Facebook, por exemplo, não realiza, obrigatoriamente, a verificação da identidade de pessoas físicas, o que permite a criação de perfis falsos e até mesmo perfis operados por inteligência artificial, os bots. Isso, no entanto, não significa que toda conta do Facebook se trata de um bot, e nem que todo mundo vai criar um perfil falso. Do mesmo modo, acessar comentários mais antigos no Facebook ou Twitter se torna muito difícil diante do que os designs dessas redes sociais possibilitam.

Qualquer pesquisa cujo corpus de análise seja composto por materiais selecionados de redes sociais, blogs, buscadores online e tecnologias digitais no geral está afetada tanto pelo big data e seus $3 \mathrm{Vs}$ quanto pelo affordance digital. Contudo, 
as limitações impostas pelo affordance das plataformas não causam, necessariamente, prejuízos às pesquisas. $\mathrm{O}$ problema surge quando pesquisadoras/es não sabem onde as limitações estão, em que ponto as ferramentas de busca não dão certo e por qual razão os resultados das buscas são falhos. Mais importante do que tentar, em vão, "driblar" o affordance, é abandonar qualquer pretensão de obter um conjunto de dados supostamente completo e imaculado pelas falhas de design e buscar conhecer o próprio campo de pesquisa digital, isto é, "adquirir um conhecimento profundo de como um conjunto de dados foi construído e usar esse conhecimento como um recurso para desenhar as abordagens analíticas apropriadas" (BROOKER et al., 2016, p. 42).

Apesar disso, muitos dos estudos sociais que têm o objetivo de fazer sentido de dados digitais não tratam dos aspectos informacionais que afetam corpus, análise e resultados (BROOKER et al., 2016), talvez pela aparente distância disciplinar, talvez por considerar que as questões políticas e técnicas do big data são pormenores em relação a problemas sociais considerados "mais importantes". Qualquer que seja a razão, é bastante comum que as considerações sobre a seleção dos dados ocupem somente poucas linhas na seção metodológica do trabalho. Assim acontece em recentes estudos etnográficos digitais do campo da investigação linguística (BIONDO, 2019; BORGES \& MELO, 2019; SILVA, 2019).

Se ainda há dúvidas da importância de discutir a respeito do que afeta os dados digitais que analisamos, deve-se lembrar o que Blommaert (2008, p. 111) fala sobre o contexto esquecido da história dos dados: "certas coisas podem apenas ser ditas em certos momentos, sob certas condições; da mesma forma, certas coisas podem apenas ser pesquisadas em certos momentos, sob certas condições", e que "na etnografia [...] reconhece-se que a maneira como os dados são obtidos, gravados e tratados pelo analista tem influência naquilo que esses dados nos dizem" (p. 110).

O exemplo que o autor usa para ilustrar seu argumento não é digital, trata-se, na verdade, da crise política sobre os pedidos de asilo que se rompeu na Bélgica, em 1998, mas essas palavras se referem à etnografia em geral, e parecem terem sido feitas para se falar de dados digitais: "certas coisas podem apenas ser pesquisadas em certos momentos, sob certas condições" - não seria isso o affordance?; "a maneira como os dados são obtidos, gravados e tratados pelo analista tem influência naquilo que esses dados nos dizem" - não é possível enxergar aqui a ação do big data? Se a influência das condições de obtenção dos dados é reconhecida pela etnografia, a etnografia digital não pode ficar de fora. No entanto, não basta reconhecer, é preciso deixar explícito em nossas análises, como apontam boyd e Crawford (2012, p. 69-70): 
Quando pesquisadoras/es se aproximam de um conjunto de dados, elas/eles precisam compreender - e explicar - não só as limitações do conjunto de dados, mas também quais perguntas elas/eles podem perguntar sobre esse conjunto e quais interpretações são apropriadas.

\section{UMA AMEAÇA FOI DETECTADA: LINGUAGEM E O CONTATO ENTRE HUMANO E DIGITAL}

Não é apenas a falta de atenção à história dos dados que está impedindo discussões sobre o caráter da comunicação pós-digital - em que a tecnologia digital está consolidada como incorporada (embodied), integrada (embedded) e cotidiana (everyday), conforme descreve Hine (2015). A incompatibilidade entre a visão de linguagem tradicional da Linguística e as práticas linguísticas contemporâneas também atua nesse cenário.

Uma visão de linguagem antropocêntrica, e seu antropocêntrico modelo de comunicação, como o circuito da fala saussuriano, "perde gradualmente sua pertinência na produção de conhecimento sobre as práticas de linguagem na contemporaneidade", uma vez que apaga "a hibridez e a pluralidade de entidades não-humanas que participam dos processos interativos e semióticos" (MARTINS \& VIANA, 2019, p. 497). As entidades não-humanas (digitais) estão em muitas interações comunicativas, sejam elas online ou offline. A conversa entre duas pessoas desconhecidas em um elevador de um prédio comercial sobre a previsão do tempo acontece porque o aplicativo fornece a previsão - e mesmo que a previsão tenha sido vista no noticiário televisivo, a equipe do jornal obteve a informação das empresas de previsão do tempo, as quais fazem a análise do big data gerado pelas milhares de estações de monitoramento climático espalhadas pelo mundo. A discussão política entre membros de uma família pode ter sido motivada pela notícia vista na página do Facebook de algum jornal, pelo texto recebido via WhatsApp ou pela postagem no Twitter de algum líder político.

Quando Blommaert (2019, p. 6) diz que "modelos de comunicação na era pós-digital precisam ser modelos em que as características do nexo online-offline sejam vistas como uma realidade que afeta a fenomenologia da comunicação no sentido mais profundo", ele está chamando à criação de novos modelos que deem conta da complexidade da experiência linguística e que abandonem a utopia de sua homogeneidade. Por sorte, ainda em 1987, Mary Louise Pratt já pensava sobre isso.

Pratt (2013[1987]) tece críticas a uma "linguística da comunidade", encontrada no pensamento de Saussure, de Chomsky, nos estudos pragmáticos, 
sociolinguísticos e discursivos, para qual uma comunidade de fala é compreendida como uma fraternidade limitada, soberana e horizontal. Para essa perspectiva,

o caso prototípico ou não marcado de língua é geralmente assumido na linguística como a fala face-a-face de falantes nativos adultos (como no diagrama de Saussure) em situações monolíngues, ou mesmo monodialetais - em resumo, o caso maximamente homogêneo linguística e socialmente. Essa é a situação em que os dados são sentidos como "mais puros", na qual você pode ver mais claramente os fundamentos de como a língua funciona, com a mínima distorção, infelicidade ou "ruído". (PRATT, 2013, p. 440-441)

Todavia, a contribuição de Pratt não é a proposta de um outro modelo de comunicação, e sim o reconhecimento da existência de uma outra Linguística, a "linguística do contato". A linguística do contato se interessa pelas práticas de linguagem que acontecem através dos limites de diferenciação social ${ }_{i}$ é uma linguística cujo foco está no contato "entre grupos dominantes e dominados, entre pessoas de diferentes e múltiplas identidades, falantes de diferentes línguas" e no "modo como essas/es falantes se constituem umas/uns às/aos outras/os relacionalmente e na diferença, como encenam diferenças na língua" (PRATT, 2013, p. 452)

Dentre os trabalhos cujo objetivo é de fato a construção de novos modelos de comunicação, estão os de Dell Hymes (1972) e Erving Goffman (1986[1974]). Ambas as propostas se empenham em considerar os vários papéis de participação de um evento de fala. O modelo de Hymes (1972) diferencia falante de endereçador, e ouvinte de endereçado. Goffman (1986[1974]) entende que o papel de falante pode ser realizado por um originador, animador, figura e mais alguns outros. Um novo modelo de comunicação que não gire em torno somente da interação entre dois indivíduos e que aceite a existência de ruídos é, então, um desafio já antigo para vertentes críticas das bases modernas do pensamento linguístico.

Adotar um único novo modelo de comunicação que faça sentido na era da comunicação pós-digital pode parecer uma boa solução tanto para substituir modelos defasados quanto para tentar limitar a agentividade digital na interação linguística, possibilitando que se avance logo para outras discussões. Irvine (1996), porém, faz ressalvas quanto a uma empreitada dessa natureza. Para Irvine, rechear um modelo de vários papeis de participação, dando-lhe mais camadas, mas ainda mantendo ideais universalistas e apegando-se à utopia linguística de homogeneidade, apenas torna mais complexo o modelo que já existe e mantém o contexto como pano de fundo. Mais do que unir todos os esforços de forma a definir um outro modelo, o foco das análises linguísticas deve ser o próprio processo de fragmentação desses papeis, isto é, como eles "são construídos, imaginados, e socialmente distribuídos" (IRVINE, 
1996, p. 136). Ou seja, teorizar sobre a linguagem abandonando a ilusão do modelo universal e sem tentativas de trancar o objeto de estudo em um arcabouço teórico.

Saber que o circuito de uma postagem no Twitter, por exemplo, não é linear e nem simétrico, que a audiência não é única, mas fragmentada (BLOMMAERT, 2019), é mais pertinente do que o próprio novo modelo de comunicação, já que não é possível que um único modelo dê conta de toda a complexidade das práticas linguísticas pós-digitais, por razões como: i) os designs dos ambientes são múltiplos - Twitter, Facebook, Instagram, YouTube ou qualquer outro ambiente digital não funcionam de uma mesma forma; ii) as pesquisas linguísticas sobre comunicação pós-digital se centram muito mais nas redes sociais do que em outras plataformas de dadificação, como buscadores, aplicativos de previsão do tempo, aplicativos de monitoramento de dados pessoais (atividade física, sono e hábitos alimentares) e aplicativos de aprendizagem de línguas; iii) as transformações de todas essas plataformas são muito mais velozes do que os vários campos dos estudos da linguagem poderiam acompanhar - mesmo que hoje se defina um modelo de comunicação para o Twitter, em um mês ele pode estar defasado.

Por isso, Linguística e Linguística Aplicada têm muito mais a ganhar com visões (assim mesmo, no plural) de linguagem que não sejam antropocêntricas (MARTINS \& VIANA, 2019), universalistas (IRVINE, 1996), que contemplem o contato (PRATT, 2013 [1987]) entre o humano e o digital e, principalmente, que estejam abertas a pensar sobre as práticas complexas das experiências linguísticas pós-digitais, sem buscar resolvê-las ou limitá-las. Visões de linguagem que não culminem em um circuito da fala revisitado, mas que provoquem "um curto-circuito na linguagem, para colapsar as bases antropocêntricas que ainda o mantêm em funcionamento" (MARTINS \& VIANA, 2019, p. 510). Visões de linguagem que vão ao encontro das próprias posições epistemológicas da Linguística Aplicada Crítica, que adota uma posição vigilante às bases modernistas e coloniais da macroárea Linguística (MOITA LOPES, 2006; PENNYCOOK, 2001; SOUSA \& PESSOA, 2019).

Enxergar a linguagem dessa maneira se configura como um rompimento com as bases mentalistas da Linguística, cuja preocupação é purificar a linguagem de aspectos sociais, removendo toda materialidade e isolando-a no porto seguro da mente, onde ela pode ser estudada sem intervenções indesejadas (IRVINE, 2017), excluindo tudo o que relacionalmente forma o antbropos para, ironicamente, colocá-lo no centro. Diversas autoras e autores têm contribuído para essa ruptura, colocando a projeção do corpo no cerne dos recursos das ações de linguagem, a exemplo de Butler (1997), Sales Jr. (2006), Povinelli (2016) e Pinto (2018). 
Ao contrário do que se poderia imaginar, pensar sobre o papel de big data, affordance e digitalização nas práticas linguísticas segue exatamente na esteira desses trabalhos, não excluindo, de forma alguma, a materialidade do corpo e da socialização do corpo nessas ações em virtude de uma suposta primazia do digital. A questão é justamente a impossibilidade de delimitar onde o digital começa e o corpo termina, e vice-versa. Como Christine Hine disse em 2015, as tecnologias digitais estão incorporadas, e como Donna Haraway disse bem antes, em 1985, "a máquina coincide conosco, com nossos processos; ela é um aspecto de nossa corporificação" (HARAWAY, 2009[1985], p. 97).

\section{ÚLTIMAS CONSIDERAÇÕES}

O intuito deste artigo era argumentar em favor da construção de olhares sobre a linguagem que não se limitem a entender que o objeto de estudo da Linguística é a transmissão de informação de mente humana para mente humana, mas que considerem as complexidades das interações linguísticas pós-digitais, para além de visões louvem ou demonizem a digitalização.

Chegar a esta Linguística implica em tecer constantes rupturas (ou, ao menos, tentativas de rupturas) epistemológicas com os fundamentos modernos, mentalistas, essencialistas e antropocêntricos que forjaram o pensamento linguístico. Por isso, nestas últimas linhas, quero enfatizar que uma estratégia de ruptura está em trabalhos que investiguem a materialidade do corpo contemporâneo, que não está todo envolto por pele (HARAWAY, 2009[1985]) e dilui os limites entre orgânico e inorgânico, organismo e máquina, mente e corpo, natureza e cultura, biológico e social, bem como tantos outros modos dualistas de compreender o mundo (FAUSTO-STERLING, 2001). A Linguística Aplicada que se preocupa em tecer caminhos críticos, antidisciplinares e transgressivos (MOITA LOPES, 2006) já se empenha em desafios neste sentido. Agora, acrescenta-se a tarefa de interpretar

os sinais crescentes de esgotamento de todas as dicotomias sobre as quais fundamentamos, e pelas quais justificamos, a arrogância que nos tornou reféns de nossa própria insensatez, 'cientificamente comprovada' pela nossa inscrição na historicidade do planeta, decretada como Antropoceno [...] (BUZATO, 2019, p. 478)

No mais, não há forma melhor de encerrar o raciocínio construído até aqui do que com as palavras de Donna Haraway (2009[1985], p. 88): como ciborgues que somos, como híbridos de organismo e máquina, nossa luta é "a luta pela linguagem, 
é a luta contra a comunicação perfeita, contra o código único que traduz todo significado de forma perfeita".

\section{$\overline{\text { REFERÊNCIAS }}$}

ANDERSON, C. (2008) The End of Theory: The Data Deluge Makes the Scientific Method Obsolete. Wired. Disponivel em: https://www.wired.com/2008/06/pbtheory/. Acesso em: 29 jan. 2020.

ARNAUT, K.; KARREBAEK, M.; SPOTTI, M. (2017) Engaging superdiversity: The poesis infrastructures nexus and language practices in combinatorial spaces. In: ARNAUT, K., et al (orgs.). Engaging superdiversity: recombining spaces, times and language practices. Bristol: Multilingual Matters, pp. 3-24.

BANSAL, S. (2016) Big data for infectious disease surveillance and modeling. The Journal of Infectious Diseases, v. 214, n. 4, pp. 375-379.

BIONDO, F. (2019) Ideologias de gênero e ideologias de língua(gem) em páginas feministas do Facebook. Alfa, v. 63, n. 2, pp. 295-315.

BLOMMAERT, J. (2008) Contexto é/como crítica. In: SIGNORINI, I (orga.). Situar a lingua[gem]. Tradução de Daniel Silva e Clara Dornelles. São Paulo: Parábola, pp. $91-115$.

BLOMMAERT, J. (2019) Political discourses in post-digital societies. Disponivel em: https://www. researchgate.net/publication/337890116. Acesso em: 29 dez. de 2019.

BLOMMAERT, J.; SMITS, L.; YACOUBI, N. (2018) Context and its complications. Tilburg Papers in Cultural Studies, n. 208. Disponível em: https://www.researchgate.net/ publication/325347012_Context_and_its_complications. Acesso em: 12 jan. 2020.

BORGES, R.; MELO, G. (2019) Quando a raça e o gênero estão em questão: embates discursivos em redes sociais. Revista Estudos Feministas, v. 27 , n. 2, pp. 1-13.

boyd, d.; CRAWFORD, K. (2012) Critical questions for big data. Information, Communication \& Society, v. 15, n. 5 , pp. 662-679.

BROOKER, P. et al. (2016) Have we even solved the first 'big data challenge?': practical issues concerning data collection and visual representation for social media analytics. In: SNEE, H. et al (orgs.). Digital methods for Social Science: an interdisciplinary guide to research innovation. Londres: Palgrave Macmillan, pp. 34-50. 
BUTLER, J. (1997) Excitable speech: a politics of the performative. Nova York: Routledge.

FAUSTO-STERLING, A. (2001) Dualismos em duelo. cadernos pagu, n. 17-18, v. 2, pp. 9-79.

BUZATO, M. (2018) Dadificação, visualização e leitura do mundo: quem fala por nós quando os números falam por si? Linguagem em Foco, v. 10, n. 1, pp. 83-92.

BUZATO, M. (2019) O pós-humano é agora: uma apresentação. Trabalbos em Linguística Aplicada, v. 58, n. 2, pp. 478-495.

FLORES, P. (2017) O que a Cambridge Analytica, que ajudou a eleger Trump, quer fazer no Brasil. Nexo. Disponivel em: https://www.nexojornal.com.br/expresso/2017/12/08/ O-que-a-Cambridge-Analytica-que-ajudou-a-eleger-Trump-quer-fazer-no-Brasil. Acesso em: 29 jan. 2020.

GOFFMAN, E. (1974) Frame analysis: an essay on the organization of expierence. Boston: Northeastern University Press, 1986.

HARAWAY, D. (1985) Manifesto ciborgue. Ciência, tecnologia e feminismo-socialista. In: TADEU, T (org.). Antropologia do ciborgue. As vertigens do pós-bumano. 2. ed. Belo Horizonte: Autêntica, 2009, pp. 33-118.

HINE, C. (2000) Virtual Ethnograpby. Longres: SAGE.

HINE, C. (2015) Ethnography for the Internet. Londres: Bloomsbury Academic.

HYMES, D. (1972) Models of the interaction of language and social life. In: GUMPERZ, J.; HYMES, D. (orgs.). Directions in sociolinguistics: the ethnography of communication. Holt, Rinehart and Winston, pp. 35-71.

IRVINE, J. (1996) Shadow conversations: the indeterminancy of participants roles. In: SILVERSTEIN, M.; URBAN, G. (orgs.). Natural bistories of discourse. Chicago: The University of Chicago Press, pp. 131-159.

IRVINE, J. (2017) Afterword: materiality and language or material language? Dualisms and embodiments. In: CAVANAUGH, J.; SHANKAR, S. (orgas.). Language and materiality: etbnograpbic and theorital explanations. Cambridge: Cambridge University Press, pp. 277-293.

KEANE, W.; SILVERSTEIN, M. (2017) Curated conversation: "Materiality: it's the stuff!" In: CAVANAUGH, J. R.; SHANKAR, S. (orgas.). Language and Materiality: ethnograpbic and theorital explanations. Cambridge: Cambridge University Press, pp. 29-40. 
MALY, I. (2018) Populism as a mediatized communicative relation: the birth of algorithmic populism. TilburgPapersinCulturalStudies, n. 213. Disponívelem: https://www.researchgate. net/publication/328095323_Populism_as_a_mediatized_communicative_relation The_birth_of_algorithmic_populism. Acesso em: 02 fev. 2020.

MARMWICK, A.; boyd, d. (2010) I tweet honestly, I tweet passionately: twitter users, context collapse, and the imagined audience. New Media \& Society, v. 13, n. 1, pp. 114-133.

MARTINS, E.; VIANA, R. (2019) Por uma visão de linguagem ciborgue e coletiva. Trabalhos em Linguística Aplicada, v. 58, n. 2, pp. 496-519.

MOITA LOPES, L. P. (2006) Linguística aplicada e vida contemporânea: problematização dos construtos que têm orientado a pesquisa. In: MOITA LOPES, L. P. (org.). Por uma linguística plicada indisciplinar. São Paulo: Parábola, pp. 85-107.

MUTSAERS, P. (2017) Should big data determine who gets pulled over? Diggit Magazine. Disponivel em: https://www.diggitmagazine.com/column/should-big-datadetermine-who-gets-pulled-over. Acesso em: 29 jan. 2020.

PENNYCOOK, A. (2001) Critical Applied Linguistics. A Critical Introduction. Londres: Erlbaum Associates.

PINTO, J. (2018) Corpo como contexto-de-ocorrência de metapragmáticas sobre o português em socializações de estudantes migrantes para o Brasil. Linguagem em Discurso, v. 18, n. 3, pp. $751-768$.

POVINELLI, E. (2016) Pragmáticas íntimas: linguagem, subjetividade e gênero. Tradução por Joana Plaza Pinto. Revista de Estudos Feministas, v. 24, n. 1, pp. 205-237.

PRATT, M. L. (2013) Utopias linguísticas, tradução por André Marques do Nascimento e Joana Plaza Pinto. Trabalbos em Linguística Aplicada, v. 52, n. 2, pp. 437-459.

RYMES, B. (2012) Recontextualizing YouTube: from micro-macro to mass-mediated communicative repertoires. Antbropology \& Education Quaterly, v. 43, n. 2, pp. 214-227.

SALES JR., R. (2006) Democracia racial: o não-dito racista. Tempo social, v. 18, n. 2, pp. 229-258.

SANTOS, V. (2016) Big data, meio e linguagem: novas tecnologias e práticas linguísticas. Dissertação de Mestrado em Letras e Linguística, Universidade Federal de Goiás, Goiânia.

SILVA, D. (2019) (Meta)pragmática da violência linguística: patologização das vidas trans em comentários online. Trabalhos em Linguística Aplicada, v. 58, n. 2, pp. 965-965. 
SOUSA, L.; PESSOA, R. (2019). Humans, nonhuman others, matter and language: a discussion from posthumanist and decolonial perspectives. Trabalhos em Linguística Aplicada, v. 58, n. 2, pp. 520-543.

SZABLA, M.; BLOMMAERT, J. (2018) Does context really collapse in social media? Applied Linguistics Review, pp. 1-29.

VARIS, P.; HOU, M. (2020) Digital approaches in linguistic ethnography. In: TUSTING, K. (orga.). The Routledge Handbook of Linguistic Ethnography. Londres: Routledge, pp. 229-240.

VARIS, P. (2014) Digital ethnography. Tilburg Papers in Cultural Studies, n. 104.

Recebido: 20/02/2020

Aceito: 24/02/2020

Publicado: 19/05/2020 